РАННЯЯ КЛЕТОЧНАЯ РЕАКЦИЯ ТКАНЕЙ ГЛАЗА НА ИМПЛАНТАЦИЮ БИОРЕЗОРБИРУЕМЫХ ДРЕНАЖЕЙ НАСЫЩЕННЫХ ИММУНОДЕПРЕССАНТАМИ С ИЗБИРАТЕЛЬНЫМ МЕХАНИЗМОМ ДЕЙСТВИЯ

1,3Германова В.Н., '2Сарбаева Н.Н., 1,3Карлова Е.В., ${ }^{1}$ Волова Л.Т., ${ }^{1}$ Нефедова И.Ф., ЗРадайкина М.В.

1Самарский государственный медицинский университет, 2Медицинский университет РЕАВИ3, 3Самарская областная клиническая офтальмологическая больница имени Т.И. Ерошевского, Самара, Россия, e-mail: vikaprokhorenko@gmail.com

\title{
THE EARLY CELLULAR REACTION OF EYE TISSUES TO THE IMPLANTATION OF BIORESORBABLE DRAINAGES SATURATED BY IMMUNOSUPPRESSANTS WITH A SELECTIVE MECHANISM OF ACTION 1,3Germanova VN, ${ }^{2}$ Sarbaeva NN, ${ }^{1,3}$ Karlova EV, ${ }^{1}$ Volova LT, ${ }^{1}$ Nefyodova IF, ${ }^{3}$ Radaykina MV
}

1Samara State Medical University, ${ }^{2}$ Medical University REAVIZ, ${ }^{3}$ Eroshevsky Samara Regional Clinical Ophthalmological Hospital, Samara, Russia, e-mail: vikaprokhorenko@gmail.com

Дия цитирования:

Германова В.Н., Сарбаева Н.Н., Карлова Е.В., Волова Л.Т., Нефедова И.Ф., Радайкина М.В. Ранняя клеточная реакиия тканей глаза на имплантацию биорезорбируемых дренажей насыщенных иммунодепрессантами с избирательным механизмом действия// Морфологические ведомости.- 2020.- Том 28.- № 3.- С. 15-20. https://doi.org/10.20340/mvmn.2020.28(3):15-20

For the citation:

Germanova VN, Sarbaeva NN, Karlova EV, Volova LT, Nefyodova IF, Radaykina MV. The early cellular reaction of eye tissues to the implantation of bioresorbable drainages saturated by immunosuppressants with a selective mechanism of action. Morfologicheskie Vedomosti - Morphological Newsletter. 2020;28(3):15-20 https://doi.org/10.20340/mv-mn.2020.28(3):15-20

Резюме. Пролонгированное применение иммунодепрессантов с избирательным механизмом действия является перспективной стратегией в профилактике послеоперационного рубцевания в хирургии глаукомы. С целью оценки клеточной реакции тканей глаза на имплантацию биорезорбируемых дренажей, насыщенных циклоспорином А, либо эверолимусом, на 12 кроликах моделировали гипотензивную операцию фильтрующего типа с имплантацией дренажей на основе полилактида. Дренажи, имплантируемые кроликам двух исследуемых экспериментальных групп, предварительно насыщали либо циклоспорином А, либо эверолимусом. Группу контроля составили животные, которым имплантировали дренажи, не насыщенные какими-либо лекарственными препаратами. На 7 день после операции животных выводили из эксперимента, глазные яблоки энуклеировали и изготавливали гистологические препараты, окрашенные гематоксилином и эозином, а также гематоксилином и пикрофуксином красным. С помощью балльной оценки по шкале от 0 до 5 анализировали клеточный состав внутри материала дренажа, интенсивность синтеза коллагена в дренаже, выраженность капсулы вокруг дренажа и количество кровеносных сосудов. В сравнении с группой контроля в исследуемых группах обнаруживали достоверно меньшее количество мононуклеаров, фибробластов и гигантских клеток инородных тел, а также менышую выраженность капсул, окружающих дренаж, вплоть до их полного отсутствия. Кроме того, достоверно ниже была интенсивность синтеза коллагена внутри материала дренажей исследуемых групп. Дренажи группы с использованием эверолимуса отличались крайне низкой плотностью жизнеспособных клеточных элементов внутри имплантированного материала и полным отсутствием коллагена. При этом токсического влияния вещества на окружающие ткани обнаружено не было. Таким образом, насыщение биорезорбируемых дренажей на основе полилактида циклоспорином А и эверолимусом способствовало снижению интенсивности формирования соединительнотканных элементов как внутри, так и вокруг дренажа в ранние сроки после операции.

Ключевые слова: глаз, клетки и ткани глаза, глаукома, биорезорбируемые дренажи, иммунодепрессанты

Summary. Prolonged use of immunosuppressants with a selective mechanism of action is a promising strategy in the prevention of postoperative scarring in glaucoma surgery. In order to assess the cellular response of eye tissues to the implantation of bioresorbable drains saturated with cyclosporin A or everolimus, a filter-type hypotensive operation with implantation of polylactide-based drains was simulated in 12 rabbits. Drainages implanted in rabbits of the two experimental groups under study were pre-saturated with either cyclosporin A or everolimus. The control group consisted of animals that were implanted with drains not saturated with any drugs. On the 7th day after the operation, the animals were taken out of the experiment, the eyeballs were enucleated, and histological preparations stained with hematoxylin and eosin, as well as hematoxylin and Picrosirius-red were prepared. Using a score on a scale from 0 to 5, the cellular composition within the drainage material, the intensity of collagen synthesis in the drainage, the thickness of the capsule around the drainage, and the number of blood vessels were analyzed. In comparison with the control group, the study groups showed a significantly lower amount of mononuclear cells, fibroblasts and giant cells of foreign bodies, as well as a lower thickness of the capsules surrounding the drainage, up to their complete absence. In addition, the intensity of collagen synthesis inside the drainage material of the studied groups was significantly lower. The drains of the everolimus 
group were characterized by an extremely low density of viable cellular elements inside the implanted material and a complete absence of collagen. At the same time, no toxic effect of the substance on the surrounding tissues was found. Thus, the saturation of bioresorbable drainages based on polylactide with cyclosporin A and everolimus contributed to a decrease in the intensity of the formation of connective tissue elements both inside and around the drainage in the early postoperative period.

Key words: eye, eye cells and tissues, glaucoma, bioresorbable drainages, immunosuppressants

Введение. Одной из самых актуальных проблем хирургии глаукомы на сегодняшний день является послеоперационное рубцевание, создающее препятствие на сформированных во время операции путях оттока внутриглазной жидкости [1-2]. Для решения данной проблемы были предложены различные модели дренажей, а также интра- или постоперационное применение препаратов с антипролиферативными свойствами. Тем не менее, до сих пор не найдено достаточно эффективного способа борьбы с послеоперационным рубцеванием, который не приводил бы к развитию серьезных, угрожающим зрению осложнений [3-4]. В настоящее время все больше внимания уделяют веществам, избирательно блокирующим те или иные звенья каскада воспаления и пролиферации для прямого или опосредованного снижения интенсивности процессов рубцевания [5]. К таким веществам относят и иммунодепрессанты, обладающие избирательным механизмом действия, в частности, циклоспорин А и эверолимус. Циклоспорин А - ингибитор кальцинейрина, избирательно ингибирующий функции Тхелперов [6]. Согласно данным некоторых авторов, циклоспорин А способен как прямо, так и опосредованно ингибировать пролиферацию не только лимфоцитов, но и фибробластов, что доказано в экспериментах на культуре клеток [7-8]. Однако механизм прямого ингибирующего действия на фибробласты на настоящий момент не изучен. Эверолимус относится к ингибиторам механистической мишени рапамицина, одной из ключевых киназ, регулирующих рост и пролиферацию клеток [9]. Микромолярные дозы эверолимуса вызывают остановку клеточного цикла в фазе G1 клеточного цикла [10]. Для пролонгированной доставки данных иммунодепрессантов к зоне операции нами ранее был разработан способ насыщения биорезорбируемых дренажей из полилактида циклоспорином А и эверолимусом [11].

Цель исследования: оценить в эксперименте раннюю клеточную реакцию тканей глаза на имплантацию биорезорбируемых дренажей, насыщенных иммунодепрессантами с избирательным механизмом действия.

Материалы и методы исследования. Эксперимент выполняли на базе Института экспериментальной медицины и биотехнологии Самарского государственного медицинского университета Минздрава России после одобрения локальным комитетом по биоэтике. В ходе исследования руководствовались Хельсинкской конвенцией о гуманном обращении с экспериментальными животными, Европейской конвенцией по защите позвоночных животных, используемых для экспериментов или в иных научных целях, приказом Минздрава России № 199-н от 1 апреля 2016 г. «Об утверждении правил надлежащей лабораторной практики». Исследование было проведено на 12 кроликах породы «Советская шиншилла» весом 3-4 кг.

Всем животным выполняли противоглаукоматозное вмешательство фильтрующего типа с имплантацией дренажа на основе полилактида. При этом животные были разделены на три равные группы. Кроликам контрольной группы имплантировали дренаж, не насыщенный лекарственными препаратами. Животным первой исследуемой группы дренаж предварительно насыщали циклоспорином А путем выдерживания дренажа в растворе циклоспорина А с концентрацией препарата 1,6 мг/мл в течение 15 минут. Дренажи животных второй исследуемой группы предварительно насыщали $2 \%$ суспензией эверолимуса путем воздействия ультразвуковых волн мощностью 630 Вт, частотой 22 кГц в течение 6 минут.

Операцию проводили с применением внутримышечного наркоза (ксилазина гидрохлорид $2 \%$ и комбинированный препарат тилетамина гидрохлорид $5 \%$ + золазепам $5 \%$ ). Вмешательство выполняли в верхнем сегменте глаза латеральнее верхней прямой 
мышцы. После разреза конъюнктивы у лимба выкраивали склеральный лоскут на $1 / 2$ толщины склеры, который отсепаровывали вплоть до обнажения ткани трабекулы. Трабекулярную ткань иссекали с формированием фистулы в переднюю камеру. Дренаж в виде муфты в сложенном состоянии шириной 2 мм, длиной 5,2 мм, толщиной 150 мкм имплантировали перпендикулярно лимбу, при этом дистальный край дренажа позиционировали под склеральный лоскут, а проксимальный - между эписклерой и Теноновой капсулой. Склеральный лоскут и конъюнктиву ушивали узловыми швами. В послеоперационном периоде животным выполняли инстилляции комбинированного препарата, содержащего ципрофлоксацина гидрохлорид 0,3\% и дексаметазона 0,1\%.

По истечении 7 дней животных выводили из эксперимента под тиопенталовым наркозом путем передозировки препарата. Глаза животных энуклеировали и помещали в раствор нейтрального формалина 10\%. Через 24 часа иссекали блок тканей зоны операции, подвергали стандартной гистологической проводке и фиксировали в парафине. Гистологические срезы изготавливали с помощью микротома MC-2 и окрашивали гематоксилином и эозином, а также гематоксилином и пикросириусом красным по стандартной методике. Для анализа отбирали по 1 репрезентативному срезу с дренажом между слоями склеры, а также между эписклерой и Теноновой капсулой. Клеточный состав внутри материала дренажа (жизнеспособные гранулоциты, мононуклеары, гигантские клетки инородных тел, фибробласты), интенсивность синтеза коллагена в дренаже, выраженность капсулы вокруг дренажа, количество кровеносных сосудов оценивали по шкале от 0 до 5. Нормальность распределения выборок проверяли с помощью критериев Колмогорова-Смирнова и Шапиро-Уилка. В дальнейшем были использованы непараметрические методы статистического анализа. Группы сравнивали между собой с помощью критерия Краскела-Уоллиса. Различия считали статистически значимыми при $\mathrm{p}<0,05$.

Результаты исследования и обсуждение. Общая клеточная реакция во всех группах в изучаемые сроки характеризовалась слабовыраженными процессами воспаления с явлениями пролиферации. Все дренажи были инфильтрированы гранулоцитами без статистически достоверной разницы между группами, что характерно для данного срока заживления раны (табл. 1). В изученных срезах отмечали малое количество макрофагов и единичные гигантские клетки инородных тел во всех дренажах за исключением группы эверолимуса (рис. 1, 2). Как в дренажах группы контроля, так и в дренажах группы циклоспорина А наблюдали фибробласты от единичных клеток до значительного количества. Статистический анализ показал, что выраженность инфильтрации фибробластами была меньше в группе циклоспорина А в сравнении с контрольной группой. В дренажах, насыщенных эверолимусом, отмечали фибробласты, гранулоциты и мононуклеары в состоянии апоптоза (рис. 3).

Нарушений жизнеспособности клеток, окружающих дренаж, не выявлено. Количество новообразованных кровеносных сосудов статистически не отличалось между группами. Интенсивность синтеза коллагена внутри дренажа, выявляемая при анализе препаратов, окрашенных гематоксилином и пикросириусом красным, была наибольшей в группе контроля (рис. 4), меньшую интенсивность коллагено-неогенеза отмечали в группе циклоспорина А (рис. 5). Признаки синтеза коллагена внутри дренажа в группе эверолимуса отсутствовали (рис. 6). Отмечалось формирование соединительнотканной капсулы различной степени выраженности вокруг дренажей, при этом капсулы дренажей, насыщенных лекарственными препаратами, характеризовались меньшей степенью выраженности и состояли в большинстве случаев из 1-3 рядов молодых фибробластов (рис. 2). Большинство дренажей контрольной группы были окружены толстым слоем коллагенового матрикса, однако, встречались и экземпляры со слабовыраженной капсулой (рис. 1, 4).

Обращает на себя внимание факт инфильтрации дренажей фибробластами при минимальном количестве макрофагов в дренажах, что свидетельствует о том, что миграция, пролиферация фибробластов в ранние сроки после операции на тканях глаза, в частности, 


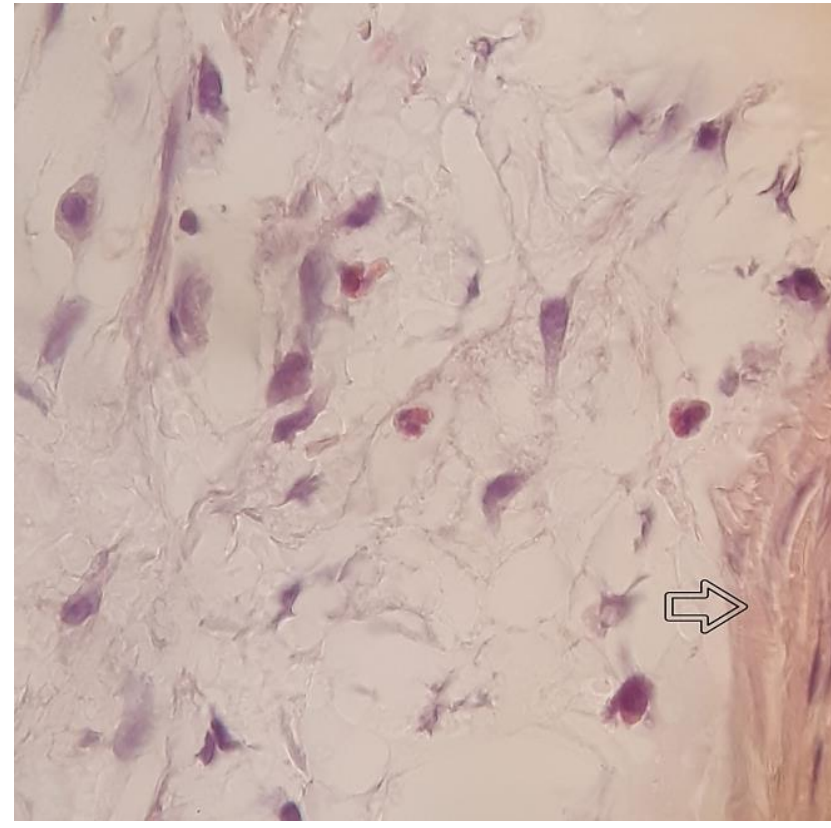

Рис. 1. Клеточный состав дренажа группы контроля через 7 дней после операции. Окр.: гематоксилином-эозин. Ув.: $\times 630$. Иммерсия. Умеренное количество фибробластов, мононуклеаров и гранулоцитов. На границе склеры и дренажа толстая капсула из зрелых фибробластов и плотного коллагенового матрикса (стрелка).

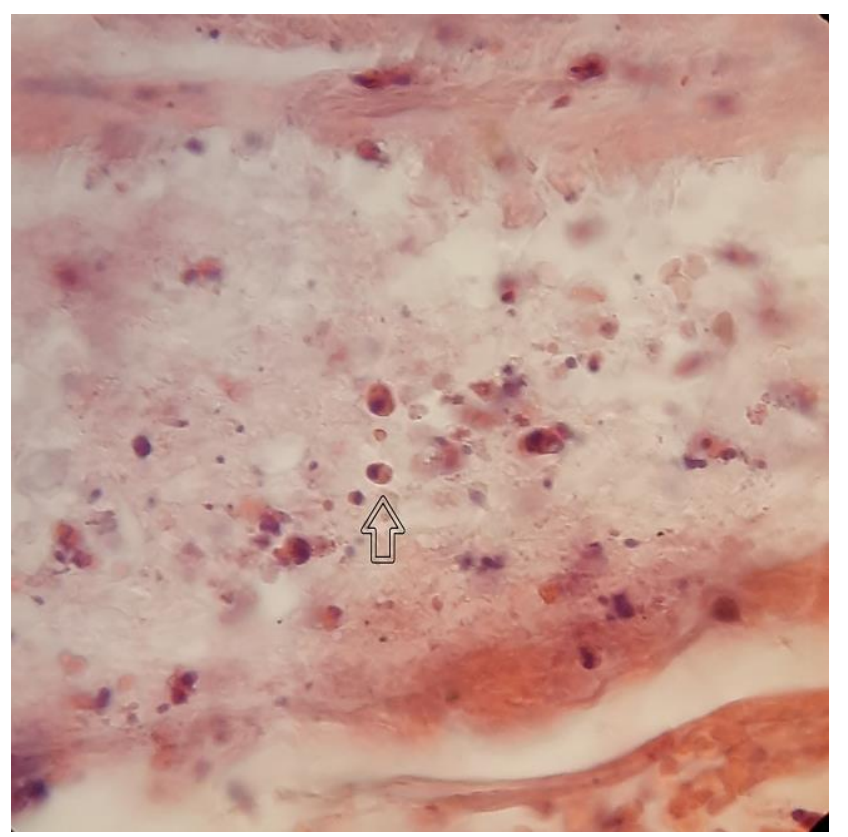

Рис. 3. Апоптоз клеток внутри материала дренажа, насыщенного эверолимусом, через 7 дней после операции. Окр.: гематоксилином-эозином. Ув.: $\times 630$. Иммерсия. Стрелкой указаны апоптозные тельца.

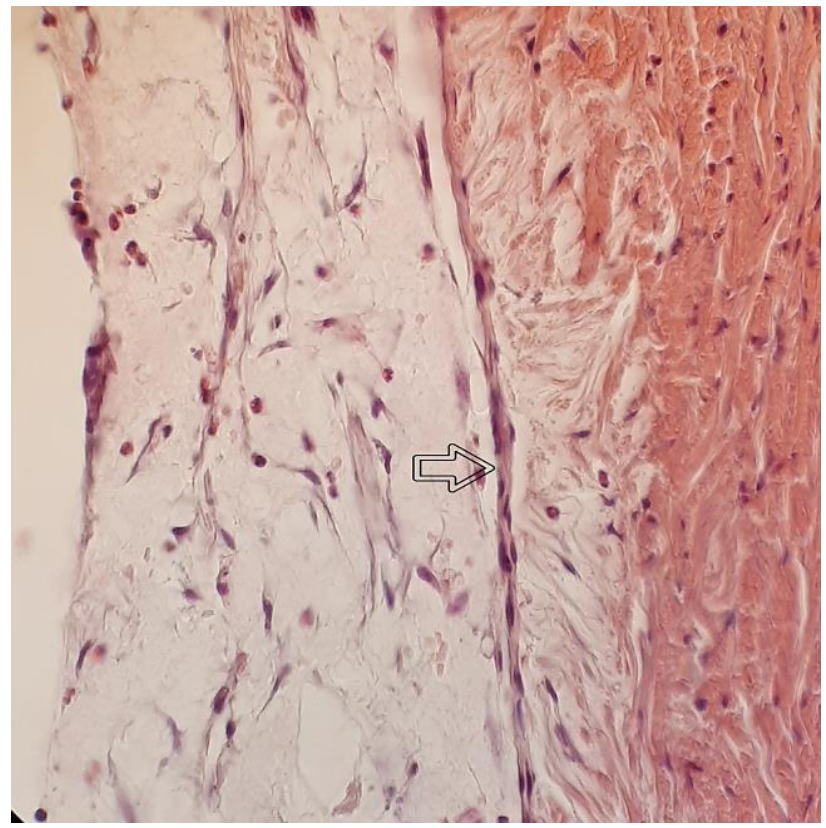

Рис. 2. Зона имплантации дренажа, насыщенного циклоспорином А, через 7 дней после операции. Окр.: гематоксилином-эозином. Ув.: х280. На границе дренажа и склеры тонкая капсула из 1-2 рядов молодых фибробластов (стрелка). Умеренное количество фибробластов, мононуклеаров и гранулоцитов.

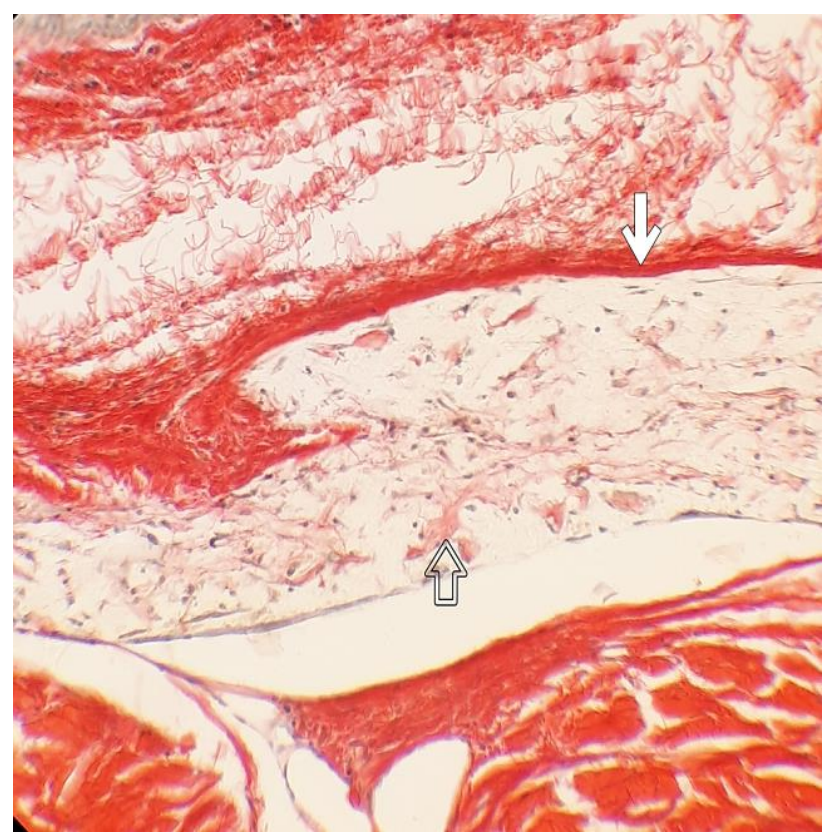

Рис. 4. Зона имплантации дренажа группы контроля через 7 дней после операции. Окр.: гематоксилин, пикросириус красный. Ув.: х70. Дренаж окружен капсулой (белая стрелка). Умеренное количество коллагена (прозрачная стрелка). 


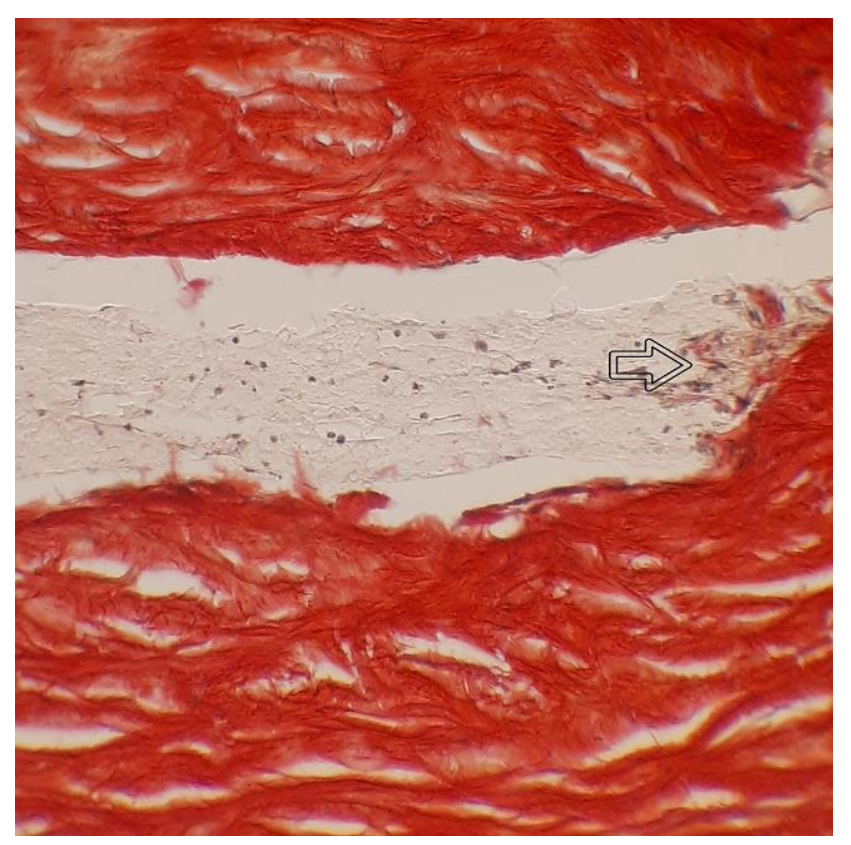

Рис. 5. Зона имплантации дренажа, насыщенного циклоспорином А, через 7 дней после операции. Окр.: гематоксилин, пикросириус красный. Ув.: х140. Небольшое количество коллагена с края дренажа (стрелка).

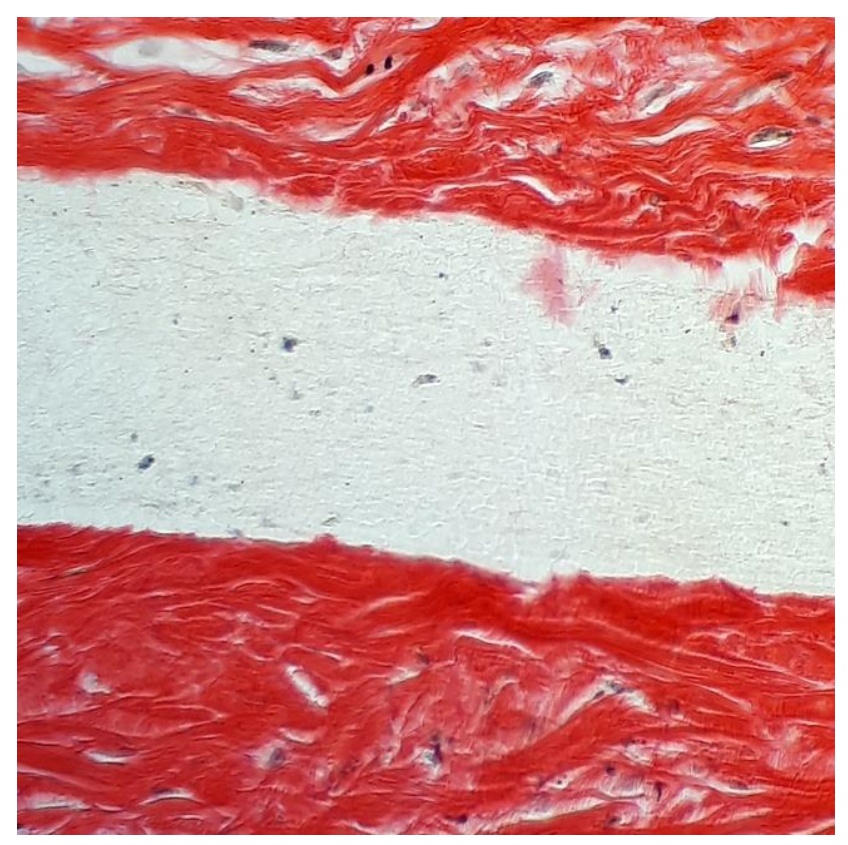

Рис. 6. Зона имплантации дренажа, насыщенного эверолимусом, через 7 дней после операции. Окр.: гематоксилин, пикросириус красный. Ув.: х140. Низкая плотность клеточных элементов в дренаже.

склере и конъюнктиве, происходит не за счет активирующего действия макрофагов, а предположительно, за счет присутствия во внутриглазной жидкости, протекающей через зону имплантации дренажа факторов роста.

\begin{tabular}{|c|c|c|c|}
\hline \multicolumn{4}{|c|}{$\begin{array}{c}\text { Таблица } 1 \\
\text { Морфологический анализ клеточной реакции на имплантацию } \\
\text { дренажей (в баллах, } \mathbf{m} \pm \mathrm{M})\end{array}$} \\
\hline Группа & Контроль & Циклоспорин А & Эверолимус \\
\hline Гранулоциты & $1,88 \pm 0,23$ & $1,88 \pm 0,30$ & $1,38 \pm 0,33$ \\
\hline Мононуклеары & $2,00 \pm 0,00$ & $1,13 \pm 0,30^{1}$ & $0,38 \pm 0,18^{1}$ \\
\hline ГКИТ & $1,38 \pm 0,42$ & $0,25 \pm 0,161$ & $0,00 \pm 0,00^{1}$ \\
\hline Фибробласты & $3,00 \pm 0,33$ & $2,13 \pm 0,23^{1}$ & $0,25 \pm 0,16^{1,2}$ \\
\hline Коллаген & $2,25 \pm 0,49$ & $1,13 \pm 0,30^{1}$ & $0,00 \pm 0,00^{1,2}$ \\
\hline Капсула & $2,88 \pm 0,52$ & $1,13 \pm 0,231$ & $0,75 \pm 0,41^{1}$ \\
\hline Сосуды & $1,13 \pm 0,44$ & $0,25 \pm 0,25$ & $0,00 \pm 0,00$ \\
\hline \multicolumn{4}{|c|}{$\begin{array}{l}{ }_{1}^{1} \mathrm{p}<0,05 \text { в сравнении с контрольной группой } \\
1,2 \mathrm{p}<0,05 \text { в сравнении с группой циклоспорина А }\end{array}$} \\
\hline
\end{tabular}

Эти факторы, трансформирующий фактор роста, фактор роста соединительной ткани, фактор роста фибробластов, фактор роста эндотелия сосудов и некоторые другие, оказывают прямое стимулирующее влияние на фибробласты. При этом применение иммунодепрессантов сдерживает активирующее влияние вышеперечисленных факторов роста на фибробласты, что выражается в уменьшении их количества в зоне имплантации дренажа в случае насыщения циклоспорином А или эверолимусом. Апоптоз клеток внутри дренажа, насыщенного эверолимусом, обусловлен высокой концентрацией вещества внутри материала дренажа. Однако отсутствие нарушений жизнеспособности клеток вокруг дренажа свидетельствует о том, что концентрации эверолимуса, выделяющиеся из дренажа вместе с током внутриглазной жидкости, а также непосредственно в окружающие ткани за счет липофильности вещества, не оказывают токсического воздействия на ткани и на ранних этапах способствуют торможению пролиферации фибробластов и формированию капсулы вокруг дренажа. 
Заключение. Таким образом, насыщение биорезорбируемых дренажей на основе полилактида циклоспорином А и эверолимусом способствует снижению интенсивности формирования соединительнотканных элементов как внутри, так и вокруг дренажа в ранние сроки после операции на глазе в эксперименте.

\section{Авторы заявляют об отсутствии каких-либо конфликтов интересов при планировании, выполнении, финансировании и использовании результатов настоящего исследования.}

\section{Литература \\ References}

1. Masoumpour M, Nowroozzadeh $M$, Razeghinejad M. Current and Future Techniques in Wound Healing Modulation after Glaucoma Filtering Surgeries. Open Ophthalmol J. 2016;10:68-85. DOI: 10.2174/1874364101610010068.

2. Zada M, Pattamatta $U$, White A. Modulation of Fibroblasts in Conjunctival Wound Healing. Ophthalmology. 2018;125(2):179-192. DOI: 10.1016/j.ophtha.2017.08.028.

3. Petrov S. Modern methods of controlling wound healing after fistulizing glaucoma surgery. Anti-inflammatory drugs and new trends. Oftal'mologiya. 2017;14(2):99-105. DOI: 10.18008/1816-5095-2017-2-99-105.

4. Petrov S. Modern methods of controlling wound healing after fistulizing glaucoma surgery. Risk factors and antimetabolites. Oftal'mologiya. 2017;14(1):5-11. DOI: 10.18008/1816-5095-2017-1-5-11.

5. Holló G. Wound Healing and Glaucoma Surgery: Modulating the Scarring Process with Conventional Antimetabolites and New Molecules. Glaucoma Surgery. 2017:80-89. DOI: 10.1159/000458488.

6. Faulds D, Goa KL, Benfield P. Cyclosporin. A review of its pharmacodynamic and pharmacokinetic properties, and therapeutic use in immunoregulatory disorders. Drugs. 1993;45(6):953-1040.

7. Leonardi A, DeFranchis G, Fregona IA, Violato D, Plebani M, Secchi AG. Effects of Cyclosporin A on Human Conjunctival Fibroblasts. Arch Ophthalmol. 2001;119(10):1512-1517. DOI: 10.1001/archopht.119.10.1512.

8. Viveiros, M.M.H., Kakizaki, F.Y., Hércules, L.A. et al. In vitro study of cyclosporine, A $0.05 \%$ on primary and recurrent pterygium fibroblasts. Int Ophthalmol 36, 237-242 (2016). DOI: 10.1007/s10792-015-0106-2.

9. Houghton P. Everolimus. Clinical Cancer Research. 2010;16(5):1368-1372. DOI: 10.1158/1078-0432.ccr-09-1314.

10. Chatterjee A, Mukhopadhyay S, Tung K, Patel D, Foster D. Rapamycin-induced G1 cell cycle arrest employs both TGF- $\beta$ and Rb pathways. Cancer Lett. 2015;360(2):134-140. DOI: 10.1016/j.canlet.2015.01.043.

11. Germanova VN, Karlova EV, Korigodskiy AR. Enrichment of a biodegradable glaucoma drainage with cyclosporine A in prevention of postoperative scarring. Zdorov'e I obrazovanie v XXI veke. 2018;20(1):29-33. DOI: 10.26787/nydha-2226-7425-2018-20-1-29-33.

\section{Авторская справка}

Германова Виктория Николаевна, аспирант, кафедра офтальмологии, Самарский государственный медицинский университет, врач-офтальмолог, офтальмологическое отделение № 3, Самарская областная клиническая офтальмологическая больница имени Т.И. Ерошевского, Самара, Россия; еmail: vikaprokhorenko@gmail.com

Сарбаева Наталья Николаевна, кандидат биологических наук, ведущий научный сотрудник лаборатории по проблемам морфологии, Научный центр доклинических исследований, Медицинский университет РЕАВИЗ, Самара, Россия; е-mail: sarbaeva@gmail.com

Карлова Елена Владимировна, доктор медицинских наук, ассистент, кафедра офтальмологии, Самарский государственный медицинский университет, врач-офтальмолог, офтальмологическое отделение № 3, Самарская областная клиническая офтальмологическая больница имени Т.И. Ерошевского, Самара, Россия; e-mail: karlova@inbox.ru

Волова Лариса Теодоровна, доктор медицинских наук, профессор, заведующая биотехнологическим отделом Института экспериментальной медицины и биотехнологий, Самарский государственный медицинский университет, Самара, Россия; e-mail: csrl.sam@mail.ru

Нефедова Ирина Феликсовна, заведующая лабораторией экспериментальной морфологии Института экспериментальной медицины и биотехнологий, Самарский государственный медицинский университет, Самара, Россия; e-mail: info@smuit.ru

Радайкина Мария Владимировна, врач-офтальмолог, офтальмологическое отделение № 3, Самарская областная клиническая офтальмологическая больница имени Т.И. Ерошевского, Самара, Россия; e-mail: masha1310@yandex.ru 